\title{
Alcohol use disorder and liver transplant: new perspectives and critical issues
}

\author{
Stefano Gitto ${ }^{1,}$, Silvia Aspite $^{1, *}$, Lucia Golfieri ${ }^{2}$, Fabio Caputo $^{3}$, Francesco Vizzutti $^{1}$, Silvana Grandi $^{2}$, \\ Valentino Patussi ${ }^{4}$, and Fabio Marra ${ }^{1,5}$
}

\begin{abstract}
${ }^{1}$ Department of Experimental and Clinical Medicine, University of Florence, Florence; ${ }^{2}$ Department of Psychology, University of Bologna, Bologna; ${ }^{3}$ Department of Internal Medicine, SS Annunziata Hospital, University of Ferrara, Cento; ${ }^{4}$ Alcohology Unit, University Hospital Careggi, Florence; ${ }^{5}$ Research Center Denothe, University of Florence, Italy
\end{abstract}

\section{Received: December 1, 2019 Accepted: March 3, 2020}

\section{Correspondence to Stefano Gitto, M.D. \\ Department of Experimental and Clinical Medicine, Univerity of Florence, Largo Brambilla 3, Florence 50134, Italy \\ Tel: +390557947845 \\ Fax: +390557949500 \\ E-mail: stefano.gitto@unifi.it https://orcid.org/0000-0002- 8042-6508}

\footnotetext{
*These authors contributed equally to this work.
}

Alcoholic liver disease is a consolidated indication for liver transplantation, but many unsolved issues can be highlighted. Patients with alcohol use disorder develop peculiar comorbidities that can become contraindications for transplantation. Moreover, a number of social and psychological patterns should be evaluated to select candidates with a low risk of alcohol relapse and adequate post-transplant adherence. In this context, the 6-month rule is too rigid to be widely applied. A short period of abstinence (1 to 3 months) is useful to estimate recovery of liver function and, possibly to avoid transplant. Cardiovascular disorders and extra-hepatic malignancies represent the main clinical issues after transplant. Patients transplanted due to alcoholic disease are a major risk for other liver diseases. Severe corticosteroid-resistant alcoholic acute hepatitis is a debated indication for transplant. However, available data indicate that well-selected patients have excellent post-transplant outcomes. Behavioral therapy, continued psychological support and a multidisciplinary team are essential to achieve and maintain complete alcohol abstinence during the transplant process. Alcoholic liver disease is an excellent indication for a liver transplant but patients with alcohol use disorder deserve a personalized approach and dedicated resources.

Keywords: Liver diseases, alcoholic; Alcoholism; Alcohol and transplant

\section{INTRODUCTION}

\section{Definition}

Alcohol use disorder (AUD) represents a prominent health problem with multi-organ involvement [1]. AUD is defined by the Diagnostic and Statistical Manual of Mental Disorders $5^{\text {th }}$ edition (DSM-V) as a spectrum of a maladaptive pattern of alcohol use that leads to a significant clinical condition or disturbance [2]. AUD is diagnosed when at least two diagnostic criteria are met in 12 months. The 11 DSM-V benchmarks for AUD include a combination of DSM-IV abuse and dependence crite- ria with "craving" added as a new parameter [2]. AUD is sub-classified into grades of severity depending on the number of criteria satisfied (mild, 2-3 criteria; moderate, $4-5$ criteria; and severe, $\geq 6$ ) [2]. This definition of AUD helps to overcome the simplified distinction between "alcoholic" and "not alcoholic" with a reduction in patient vilification and loss of self-respect [3].

Notably, the International Statistical Classification of Diseases and Related Health Problems 1oth Revision defines alcohol consumption as "harmful" when it causes a health impairment at large that can be either mental or physical [4]. Definitions of alcohol consumption 
characteristics, such as the type of drinks consumed and the duration and pattern of drinking, are essential in clinical practice because these aspects play a key role in alcohol-related injuries [1]. Quantifying alcohol consumption is not always easy in everyday practice. For this reason, the European Association for the Study of Liver and the World Health Organization (WHO) have suggested standardizing the measure of one standard "drink" of pure alcohol as $10 \mathrm{~g}$ [1]. Heavy episodic drinking is defined as $>60 \mathrm{~g}$ of pure alcohol consumed on one occasion [5] while binge drinking is ingesting four or more drinks for females or five or more drinks for males during a short period [6].

\section{Epidemiology}

AUD leads to a wide variety of problems resulting in health, social and economic burdens on society at large. The WHO has identified alcohol consumption as the cause of approximately $6 \%$ of all deaths worldwide, and $5.1 \%$ of the global burden of disease and injury [7]. Data regarding alcohol-related mortality are mainly obtained by the codification of death certificates, which has varied reliability among countries. Also, there is an undetermined proportion of alcohol-related deaths that are not explicitly mentioned on death certificates, at least partially because of a patient's tendency to underreport alcohol addiction. Consequently, an overall underestimate of the global alcohol-associated disease can easily be demonstrated [8].

Alcohol-related morbidity and mortality vary with gender, and the highest number of alcohol-attributable deaths occur among males [7]. The WHO reported a geographical distribution of alcohol-related harm with the highest fractions reported in the WHO European Region, even with consistent variability between countries and over time. The European mean alcohol consumption per person is 10.9 L per year [7] with an overall tendency to decrease in all European regions, particularly in west-central Europe and in Mediterranean regions with a simultaneous increase in the southeastern part of the region [7,9].

Despite the fact that alcohol consumption levels are higher in rich countries, alcohol-related morbidity and mortality are more frequent in poorer states [1]. Detrimental alcohol use not only harms alcohol users but also other people, such as relatives, friends, co-workers, and even strangers. Alcohol consumption leads to both intentional and unintentional injuries, such as automobile accidents, violence and self-damaging actions with higher lethality in youth [10-12].

\section{Alcohol and liver damage}

Alcohol plays an important role in a multiplicity of diseases. The harmful effects of alcohol consumption on health are evident mainly in cardiovascular disease (CVD), gastrointestinal diseases and tumors [13]. The disease burden attributable to alcohol is the highest for liver diseases, mainly cirrhosis, reaching $41 \%$ of alcohol-related liver deaths, and foetal alcohol syndrome [7]. A close dose-response correlation has been reported between the amount of alcohol consumed and the development of alcoholic liver disease (ALD) and the risk emerges at a very low quantity [14,15]. Furthermore, the development of ALD can be influenced by drinking pattern (e.g., episodic, binge, or continuous) [16], frequency of consumption, gender and ethnicity [1]. A wide range of liver diseases, either acute or chronic, can develop from alcohol consumption [17]. Progressive and repeated liver injury is conducive to cirrhosis in 10\% to $35 \%$ of heavy drinkers [17]. ALD is often discovered in the late phase with clinical complications because it is usually asymptomatic and consequently difficult to manage [1].

ALD ranges from asymptomatic steatosis to symptomatic cirrhosis and its complications, and this process can be classified into acute alcohol-related hepatitis (AAH), severe alcohol-related hepatitis (SAH), chronic ALD, acute-on-chronic ALD, and hepatocellular carcinoma (HCC) due to ALD [17]. Notably, ALD-related cirrhosis (with or without HCC) is one of the most common and consolidated indications for liver transplantation (LT) $[18,19]$, while AAH and SAH remain controversial indications [1]. Treatment options for ALD are limited and at the minimum include treating the underlying AUD, eventually together with LT. Given the increasing burden of disease and mortality in the setting of organ shortages, it is mandatory to select candidates judiciously, to optimize organ allocation.

\section{Aims}

Despite the relevance of AUD in healthcare and its importance as an indication for LT, the following challenging issues remain partially or completely unsolved: 
Do patients with AUD deserve specific pre-LT selection protocols?

What is the clinical meaning of alcohol relapse?

Do ALD recipients develop specific complications compared to other aetiologies?

Should AAH be considered an absolute contraindication to LT?

Are there transplant-specific psychosocial interventions for patients with ALD?

\section{SELECTION OF CANDIDATES FOR LIVER TRANSPLANTATION DUE TO ALCOHOL-RELAT- ED CIRRHOSIS}

LT is indicated in patients affected by end-stage liver disease in whom it would increase life expectancy, regardless of the aetiology of the liver disease. LT should be considered when a patient with cirrhosis develops major complications after applying the Model EndStage Liver Disease (MELD) score to assess the severity of the liver disease, the timing of transplantation and prioritisation of organ allocation $[20,21]$. In general, both indications and contraindications for LT in patients with ALD cirrhosis are the same as those for patients with cirrhosis of any aetiology [22]. ALD is one of the most common indications for LT in western countries $[18,19]$ and is also one of the most controversial in terms of prioritisation. Moral judgment on what is considered a self-inflicted disease might influence public opinion [23-25]. However, ethical principles recommend whole and effective treatment of these patients without discrimination [26-30].

Today, many ALD patients have no access to an LT program. Kotlyar et al. [31] demonstrated that 100,000 patients per year with ALD and decompensated ALD-related cirrhosis could be candidates for LT. Nevertheless, only $10 \%$ were referred, and only 1,200 underwent LT in 2018. Thus, every year, $4 \%$ of patients with decompensated ALD-related cirrhosis are on the waiting list and $1.2 \%$ undergo LT. This pattern of referral may lead to as many as 12,000 deaths per year [31].

\section{Clinical peculiarities of patients with ALD waiting for LT}

Patients with ALD have many clinical peculiarities due to multisystem alcohol-related damage. Remarkably, these disorders can become contraindications for LT. Patients with ALD have to be diagnosed early and treated. These comorbidities can be neurological, cardiac, haematological, gastrointestinal, musculoskeletal, or psychiatric [21,32-35]. The presence of these disorders must be carefully evaluated before LT, as they cannot only contraindicate LT but also per se negatively alter LT outcome [33,36].

\section{Neurological disease}

Alcohol is a well-known cause of brain atrophy and dementia [37]. Patients with ALD-related cirrhosis may develop mild-to-moderate short- or long-term memory issues or more severe manifestations. There may be deficits in attention, concentration, learning, abstract reasoning or motor skills. These clinical manifestations may or may not be fully reversible after stopping the consumption of alcohol [38]. Wernicke's encephalopathy is an alcohol-related syndrome characterized by ataxia, ophthalmoplegia and confusion, often with associated nystagmus, peripheral neuropathy, cerebellar signs and hypotension. Wernicke-Korsakoff syndrome can develop after Wernicke's encephalopathy. It is characterized by anterograde and retrograde amnesia and confabulation. Wernicke-Korsakoff syndrome is determined by a chronic thiamine deficiency, resulting in damage to the thalamic nuclei, mammillary bodies, brainstem and cerebellar structures. Other neurological conditions associated with chronic alcohol consumption are cerebellar degeneration, polyneuropathy, headache, neurocardiogenic syncope, compromised olfactory function, sleep disturbances, and peripheral vertigo [39].

\section{Cardiovascular disorders}

Cardiomyopathy, hypertension and supraventricular arrhythmias are the most common complications of ALD patients. In particular, alcoholic cardiomyopathy is the most common type of non-ischemic cardiomyopathy in Western countries (around $45 \%$ of cases) and has to be considered in differential diagnosis with cirrhotic cardiomyopathy in the LT setting [19]. A chronic alcohol habit is associated with a higher risk of cardiovascular (CV) mortality due to its epidemiological associations with consolidated risk factors, such as smoking, age > 50 years, dyslipidaemia, obesity and hypertension. Interestingly, arrhythmias, such as atrial fibrillation, supra- 
ventricular tachycardia, and ventricular arrhythmias, are commonly associated with both acute alcohol intoxication and withdrawal [19].

\section{Gastrointestinal comorbidities}

Mallory-Weiss tears are a major cause of gastrointestinal bleeding, and an alcohol habit can be found in more than $40 \%$ of cases [40]. Diffuse oesophageal spasm is also more common in subjects who use alcohol. Alcohol-related disease accounts for about $30 \%$ of all cases of pancreatitis. The risk of pancreatitis in this subgroup of patients is four-fold higher than that in the general population. Chronic pancreatitis develops in $10 \%$ of alcohol addicts after 6 to 12 years of $80 \mathrm{~g}$ of daily alcohol intake with a relevant impact on the nutritional status [41].

\section{Changes in the haematopoietic system}

Alcohol inhibits platelet and white blood cell functions, which increases the risks of bleeding and infections [39]. Blood loss can favour anaemia due to iron deficiency, which can occur due to the gastrointestinal diseases mentioned above. Dietary folate deficiency can cause megaloblastic anaemia. Alcohol also has a direct toxic effect on bone marrow, which can lead to sideroblastic anaemia that resolves after alcohol is withdrawn. Alcohol also inhibits megakaryocyte production causing thrombocytopenia, which quickly resolves about 1-week stopping alcohol intake [39].

\section{Infectious diseases}

Alcohol consumption is associated with an increased risk of infections, such as epidural abscesses, tuberculosis, meningitis, pneumonia, tick-borne fever and others. In particular, alcohol negatively alters the function of cells of the innate immune system, such as monocytes, macrophages and dendritic cells. Notably, alcohol is associated with increased intestinal permeability to endotoxins, altered proportions of monocyte population subsets and altered cytokine profiles, which are all patterns of increased infection risk [42].

\section{Psychiatric comorbidities}

Psychiatric illnesses are commonly associated with AUD. Anxiety and other mood disorders are found in at least one-third of patients with AUD and multiple drug use is also prevalent. Alcohol may be used as a "medication" to relieve symptoms and its chronic use may lead to the development and/or worsening of these symptoms, either by compromising social skills or through a direct effect of alcohol on the brain [43]. The patient's history of alcohol and other substance use, such as tobacco, opioids and illicit/recreational drugs should be assessed [22]. Psychiatrists, psychologists, social workers and dependency specialists are crucial when evaluating these patients for LT. The information collected helps the multidisciplinary team to determine whether a transplant can be successfully performed in the patient, as well as to create a pre- and postoperative plan $[22,44,45]$.

\section{Nutritional assessment}

Patients with AUD and cirrhosis often show relevant loss of weight and muscle mass as well as deficiencies in both macronutrients and micronutrients $[46,47]$. Furthermore, alcohol can cause fatigue and asthenia $[48,49]$. Malnutrition is diagnosed in about two-thirds of patients with cirrhosis on the LT waiting list and negatively impacts survival, quality of life and the patient's ability to cope with surgery or infections. Notably, ALD represents a relevant determinant of malnutrition in comparison with other liver diseases [50,51].

\section{Prediction of alcohol relapse and the 6-month rule}

Pre-LT alcohol abstinence represents one of the most controversial questions on this topic. The main predictors of alcohol relapse are summarized in Table 1. Many transplant centers consider the criterion of 6-month abstinence (6-month rule) to establish whether ALD patients can receive livers. Notably, this rule allows the patient's liver a chance to recover and reduces the risk of alcohol relapse [52-55]. However, the 6-month rule presents some limitations: (1) improved liver function usually occurs during the first 3 months of abstinence; (2) pre-LT abstinence is only one of the factors that might influence the risk of alcohol relapse; (3) a relevant proportion of candidates could die before achieving the 6-month abstinence period [23].

Chuncharunee et al. [56] analysed the probability of alcohol relapse and its predictors through a systemic review and meta-analysis. The authors reported that the alcohol relapse rate and heavy alcohol relapse rate, defined as harmful alcohol consumption [27], were $22 \%$ and $14 \%$ respectively. Other authors have reported that 
Table 1. Main predictors of post-transplant alcohol relapse

\begin{tabular}{|c|c|c|c|c|}
\hline Predictor of relapse & Strength & Weakness & $\begin{array}{l}\text { Meta-analysis } \\
\text { confirmation }\end{array}$ & Reference \\
\hline $\begin{array}{l}\text { 6-month pre-transplant } \\
\text { abstinence }\end{array}$ & $\begin{array}{l}\text { Possibility of liver function } \\
\text { recovery }\end{array}$ & Excessive strictness & Yes & {$[27,28,52-56,59-66]$} \\
\hline Psychiatric comorbidities & Clinical diagnosis & $\begin{array}{l}\text { Lack of distinction } \\
\text { between type of } \\
\text { disorder }\end{array}$ & Yes & {$[19,27,57-59]$} \\
\hline Low social support & $\begin{array}{l}\text { High risk of lack of } \\
\text { adherence }\end{array}$ & Nebulous definition & Yes & {$[66]$} \\
\hline $\begin{array}{l}\text { Family history of alcohol } \\
\text { abuse }\end{array}$ & $\begin{array}{l}\text { Minor chance of valid } \\
\text { caregiver }\end{array}$ & Difficult detection & Yes & {$[66]$} \\
\hline Absence of care-giver & Feature of low compliance & None & No & {$[28]$} \\
\hline
\end{tabular}

psychiatric comorbidities [19,27,57-59] and pre-LT abstinence less than 6 months [27,28,59-65] are the most significant variables predicting alcohol relapse. These results were comparable to the ones obtained in a previous meta-analysis by Dew et al. [66]. Dew et al. [66] considered 12 potential psychosocial risk factors for any kind of alcohol relapse after LT and showed that only three were significantly correlated with alcohol relapse, including low social support, a family history of alcohol abuse and pre-transplant abstinence $\leq 6$ months. Notably, the association between these psychosocial variables and alcohol relapse was modest in size and not strong enough to predict the risk of recurrence accurately [66]. Both of these meta-analyses concluded no strong statistical evidence for indiscriminate use of the 6-month rule.

The American Association for the Study of Liver Diseases, the European Association for the Study of the Liver, the United Network for Organ Sharing (UNOS) and the French Consensus Conference clearly stated that 6 months of zero alcohol consumption before LT should no longer be an absolute rule or a defining factor to determine whether a patient can be accepted onto the waitlist $[24,52,67-69]$. It must be emphasized that a minimum period of abstinence ( 1 to 3 months) is useful to recover liver function and to assess the possibility of avoiding LT [38].

Given the complexity of the setting as well as the organic, social and the psychological nature of AUD, it is not surprising that other patterns or conditions, other than the "rigid" concept of length of sobriety, might predict the risk of alcohol relapse and, more generally, the adherence of patients to a transplant program. In particular, conditions, such as psychiatric co-morbidity [27], absence of a companion in life and/or the presence of young children [28] represent independent predictors of alcohol relapse. In contrast, patient recognition, family support, employment, permanent residence and sharing a rehabilitation program correlate with a low risk of recidivism and optimal adherence [22,26].

\section{CLINICAL IMPACT OF ALCOHOL RELAPSE}

No standardized definition of alcohol relapse has been widely approved. Therefore, the reported percentages vary widely among studies due to different definitions and follow-up periods. However, it is particularly important to discriminate between patients who sporadically drink small amounts of alcohol from those who habitually drink moderate amounts and from those who continuously drink large amounts of alcohol [45]. The risk of alcohol consumption relapse after LT is estimated to be $15 \%$ to $40 \%$ over 5 years $[70,71]$.

Kodali et al. [72] reported that prevalence was as high as $26.3 \%$ over a median follow-up of 6 years; in particular, the authors demonstrated an annual rate of $4.7 \%$ for any alcohol use and $2.9 \%$ for heavy alcohol intake. The most important finding of this study was the three-fold increased risk of death within 10 years in relapsers com- 
pared to abstainers [72]. Many other studies have shown that alcohol relapse could lead to a significant worsening of the survival rate compared to abstinence [73]. Therefore, transplant recipients, considering the risk of loss of control or craving, should be supported to remain completely abstinent throughout their life $[1,24,70,73,74]$. Few data are available about the potential impact of alcohol relapse on the quality of life of transplant recipients and their family members [75].

Prevention and early diagnosis should be mandatory given the clinical influence of alcohol relapse and the potential social effects of this condition. Although self-reported alcohol use is usually of little value, biomarkers can be a supportive replacement. In particular, metabolites of alcohol, such as ethyl glucuronide, can disclose alcohol use 3 to 4 days after the last drink was consumed [76].

\section{SPECIFIC POST-TRANSPLANT CLINICAL ISSUES}

CVD and extra-hepatic malignancies represent the leading causes of long-term mortality in LT recipients [77]. CVD represents one of the most common reasons for death in ALD patients who remained abstinent or with a non-harmful drinking pattern behavior. However, recurrence of HCC and other alcohol-related malignancies is usually observed in patients who relapse with alcohol [28]. The risk of a CV event ranges from $10 \%$ at 5 years post-LT to $25 \%$ at 10 years $[78,79]$. This high incidence of CV events can be at least partly explained by the presence of pre-transplant CV risk factors. Moreover, postLT conditions, such as immunosuppressive agents and de novo metabolic syndrome features, play a significant role $[23,80-82]$. The prevalence of metabolic syndrome in LT recipients is 60\% [83]; that of diabetes mellitus is $10 \%$ to $64 \%$, that of obesity (body mass index $>30 \mathrm{~kg} / \mathrm{m}^{2}$ ) $24 \%$ to $64 \%$, that of dyslipidaemia is $40 \%$ to $66 \%$ and that of arterial hypertension is $40 \%$ to $85 \%$ [84]. The risk of a CV event doubles in patients who develop hypertension or diabetes during the post-LT period [85]. Immunosuppressive therapy can worsen prior CVD and determine the onset of de novo arterial hypertension, dyslipidaemia, diabetes and obesity [86]. As CVDs are responsible for nearly one-quarter of long-term deaths [79,86], these disorders must be identified and promptly treated even by modifying an immunosuppressive regimen [23].

The incidence of de novo malignancies ranges between 3.1 and $14.4 \%[87,88]$, representing the first cause of death in patients surviving at least 1 year after LT. In particular, de novo cancer accounts for approximately $40 \%$ of deaths $[86,89]$. The status of the transplant recipient correlates with twice the risk of developing a de novo malignancy compared to the general population [90].

The higher incidence is not the only feature of malignancies in transplant recipients. Malignancies are generally more aggressive, show an earlier onset and have a more relevant impact on survival (with mortality rates of $55 \%$ ) compared with analogous disorders occurring in the general population [91,92].

Post-transplant lymphoproliferative disorders are the most common malignancies described in LT recipients (20\% of cases) [92]. Kaposi sarcoma represents another frequent type of cancer with an incidence similar to head and neck neoplasms (17\%). Then, we see oesophageal tumors (12\%), lung cancer (10\%), gastric cancer (7\%) and, less frequently, melanoma, colorectal cancer, cervical cancer, and breast cancer [92].

Intensity and length of immunosuppression [93,94], age and pre-LT liver disease $[77,86]$ are the main predictors of de novo malignancies with some relevant differences according to the tumor site. Notably, ALD correlates with an increased occurrence of skin malignancies when compared to other liver diseases [95,96]. Alcohol is a well-known risk factor for developing oesophageal and gastric tumors [97] that occur more often in LT recipients with ALD [32,96,98]. Furthermore, higher rates of lung cancer [99] and head and neck cancers [100,101] are detected in patients transplanted for ALD. It can be difficult to establish the real burden of alcohol consumption compared to tobacco use as a risk factor for cancer development. Alcohol increases the carcinogenic consequences of smoking [102] and the epidemiological association between smoking and heavy drinking is very strong [103].

\section{OVERALL POST-TRANSPLANT OUTCOME OF ALCOHOLIC CIRRHOSIS}

Patients transplanted because of ALD usually show a satisfying overall outcome, comparable to the other 
main aetiologies $[19,104,105]$. Patient survival rates after LT for ALD are $81 \%$ to $92 \%, 78 \%$ to $86 \%$, and $73 \%$ to $86 \%$ at 1,3 , and 5 years, respectively [106]. The European Liver Transplant Registry [107] analysed data from 121,546 patients who underwent LT during 1968 to 2015 in Europe. Survival rates for ALD recipients $(\mathrm{n}=22,648)$ at 1,5 , and 10 years after LT were $86 \%, 73 \%$, and $59 \%$, respectively. These percentages were greater than those for hepatitis $\mathrm{C}$ virus (HCV) $(80 \%, 65 \%$, and $53 \%), \mathrm{HCC}(83 \%, 62 \%$, and $49 \%)$, acute liver failure (70\%, 64\%, and $58 \%)$, and hemochromatosis $(76 \%, 66 \%$, and $53 \%)$, but comparable to those registered for patients with ALD plus HCV or hepatitis B virus (HBV) $(85 \%, 69 \%$, and $54 \%)$ and slightly lower than those described for patients with cholestasis (87\%, $78 \%$, and $70 \%)$, autoimmune hepatitis $(85 \%, 76 \%$, and $67 \%)$, and $\operatorname{HBV}(83 \%, 74 \%$, and $68 \%)$.

A recently published large meta-analysis [108] indicated that LT significantly reduces mortality of ALD patients (relative risk [RR], 0.25 ; 95\% confidence interval $[\mathrm{CI}]$, 0.13 to $0.46 ; p<0.02)$. Moreover, LT decreases the relapse risk ( $\mathrm{RR}, 0.25 ; 95 \% \mathrm{CI}, 0.14$ to $0.45 ; p<0.01)$ if the analysis is restricted to prospectively collected data [109-112]. In fact, limiting the analysis to prospectively collected data exceeds the substantial heterogeneity of a random effects meta-analysis but it can slip on smallstudy effects [108]. Because of the complexity of AUD, further studies are mandatory to characterize its severity, treatment (medication and behavioral therapies) and spectrum more fully, to overcome low reproducibility and methodological heterogeneity [108].

\section{ACUTE ALCOHOLIC HEPATITIS AND LIVER TRANSPLANT}

AAH is defined by rapid onset of jaundice because of alcohol intake [113]. Ascites, gastrointestinal haemorrhage or encephalopathy represent the first clinical signs in patients with severe liver disease. Underlying cirrhosis (often undiagnosed) is present in the vast majority of cases [114]. The National Institute on Alcohol Abuse and Alcoholism (NIAAA) Alcoholic Hepatitis Consortia recommend the following standard criteria for defining alcoholic hepatitis: jaundice onset within 8 weeks, ongoing heavy alcohol intake for at least 6 months with less than 60 days of abstinence before the jaundice, aspartate transaminase (AST) > 50 IU/L, AST/ alanine transferase ratio $>1.5$ and serum total bilirubin $>3 \mathrm{mg} / \mathrm{dL}$ [115]. Moreover, a liver biopsy remains indicated in the presence of a doubtful diagnosis [115].

Alcoholic hepatitis represents a subgroup of ALD, accounting for $10 \%$ of ALD-related deaths [116]. Few effective medical therapies exist for alcoholic hepatitis [117], and LT as rescue therapy for SAH remains controversial. Patients with SAH are not considered acceptable candidates for LT as they frequently cannot satisfy the 6-month rule with a hypothetical unacceptable risk of alcohol relapse. In fact, to wait for a relevant period of abstinence before LT is often unfeasible for the very high short-term mortality risk ( $75 \%$ to $90 \%$ of deaths within 2 months) [118]. The very high mortality and lack of effective therapies indicate that early LT can be a concrete therapy option.

Early identification of patients with a high probability of short-term mortality is mandatory. Maddrey's discriminant function, the MELD, age-bilirubin-international normalised ratio-creatinine, Glasgow Alcoholic Hepatitis Score, and the Lille model all show predictive ability [119]. Corticosteroids represent the only evidence-based drug option for treating SAH other than alcohol abstinence and treatment of decompensated liver disease [120].

Notably, many scores have been developed to predict the survival of patients with AAH. Among them, the consolidated MELD score has a solid role. Moreover, Maddrey's score is useful to determine the indication for the use of corticosteroids (in patients with the worst prognosis, score > 32) [119]. The Lille model was proposed in 2007 , which differs in utilizing both baseline values and the day 7 serum bilirubin level [118]. The Lille score can be used to assess the clinical response to 7-day of corticosteroids. LT can be avoided in responders while transplant is the only therapeutic option in non-responders.

In 2011, Mathurin et al. [109] conducted a pilot study of early LT for SAH with restrictive inclusion criteria: first liver decompensating event, nonresponse to medical therapy, absence of severe comorbid disorders and motivation for abstinence. Using these criteria, only $7.7 \%$ of patients with SAH were eligible for LT. A survival benefit was demonstrated, with 6-month survival of $77 \%$ in the LT group (relapse percentage of $12 \%$ ) and 
$23 \%$ in the non-LT group, respectively. Considering data from the UNOS (2004 to 2010) [121], 5-year graft and patient survival were similar in patients transplanted for AAH and alcoholic cirrhosis (75\% vs. $73 \%$ and $80 \%$ vs. $78 \%$, respectively).

A recently published meta-analysis [122] investigated survival and alcohol relapse rate in patients transplanted for SAH (by definition without 6 months of alcohol abstinence). The authors conducted two different studies. The first study compared early LT with medical therapy alone in patients with SAH not responding to medical therapy. The second study analysed the postLT outcomes of patients transplanted for SAH and ALD cirrhosis. The first meta-analysis showed a clear 1-year survival benefit of the LT group compared to the medical therapy group. The second study showed no differences in 1, 3, or 5-year survival between patients transplanted for SAH of alcoholic cirrhosis. Finally, there were no differences in the alcohol relapse rate between the two subgroups.

\section{BEHAVIORAL INTERVENTIONS}

Adopting a comprehensive AUD treatment for the pre and post-transplant periods is mandatory [123] because abstinence from alcohol represents a prerequisite to enter the transplant list [23] and recurrence of alcohol consumption after LT negatively alters long-term survival [73]. The main goal of patients with AUD, particularly during the transplant process, is to reach and maintain abstinence. Psychosocial interventions are a crucial treatment component to achieve this purpose [124].

This approach can be challenging in ALD patients due to medical and psychiatric comorbidities [125]. Possible interventions vary widely in their content, length, and direction [123]. The intensity and duration of behavioral interventions for alcohol use are controversial, but some show a positive relationship between the length of therapy and maintenance of sobriety $[126,127]$. Emerging evidence suggests that integrating the transplant setting with addiction therapy should be an optimal goal $[126,128]$. One study demonstrated that the degree of this integration could bring encouraging outcomes [128]. Behavioral interventions for alcohol are most useful for increasing abstinence rates if put into effect during both the pre and post-transplant periods [64]. Acting after LT can be more difficult due to concomitant medical issues [25] but some groups have carried it out with benefit $[64,126,128]$. Cognitive behavioral therapy, included in a multi-component intervention, can be effective $[126,128]$. Defining a skill-based plan $[129,130]$ might be suitable for highly motivated subjects (such as people waiting for LT) [123]. Another possible intervention is so-called "motivational enhancement therapy" [131], which would be appropriate for LT candidates with low insight or who have lapsed $[125,132]$. Abstinence contracting is relatively spread out over transplant centers [133] but its role in facilitating abstinence has been questioned [134]. Behavioral and psychosocial interventions are feasible and useful for treating AUD in the setting of LT recipients and candidates and usually takes place in a multidisciplinary context [123].

In general, a multidisciplinary transplant team should include an expert psychologist and psychiatrist for early diagnosis and effective treatment of pre-transplant mental illness [135]. Particularly in the specific setting of AUD, the multidisciplinary team should perform a quick and effective evaluation of social support, adequate training about the LT process and an early psychological/psychiatric diagnosis. The multidisciplinary team should favor the development of mechanisms, such as active coping, that improve the overall clinical outcome [135].

No study has proposed a specific psychological approach for the LT setting. However, as we have recently reported [135], the following suggestions are suitable for the design of further studies: (1) any psychological approach beneficial for achieving an active coping strategy; (2) family therapy might be beneficial; (3) group or self-help group therapy seem to be beneficial for patients with a history of illicit drug use or AUD; indeed, also in the transplant context, these kinds of therapies might determine positive outcomes.

\section{CONCLUSIONS}

ALD and non-alcoholic steatohepatitis represent the true future challenge for the transplant community. 
Patients with ALD are candidates for LT according to consolidated indications represented by worsening of liver function (MELD > 15), one or more complications of portal hypertension and/or HCC. In this way, patients are often approached equally concerning other indications, such as viral infection. However, there are many clinical conditions present in patients with ALD that might represent or be contraindications for LT. Patients with ALD deserve a specific pre-LT screening program. At the same time, psychological and addiction support should start early during the transplant process despite the length of abstinence. Familial and social support should have absolute priority in this specific setting. Patients transplanted for ALD should be followed-up in three ways. The transplant team should verify the constant presence of a caregiver and social support and should guarantee an intensive psychological support program. These are essential issues to reduce the risk of relapse that seems to negatively alter long-term survival. Secondly, the CV risk profile should be specifically considered. In this regard, limitations on consolidated risk factors associated with an alcohol habit, such as tobacco use, are mandatory. Cancer surveillance should be personalized and reinforced, as patients transplanted for ALD show specific risk profiles. Sufficient evidence exists to consider well-selected patients with SAH as good candidates for LT. The length of sobriety should not be considered the only predictor of a good outcome in patients with ALD, including those with SAH. Other stronger factors are valid predictors of post-LT abstinence and optimal adherence. Active family members, a valid caregiver, social support, motivation, multidisciplinary care and the absence of major psychiatric comorbidities are the best predictors. Notably, different from the length of sobriety, the vast majority of them are changeable with wide and aggressive multi- and interdisciplinary work. An inter- and multidisciplinary approach is the only effective work approach in the transplant context, especially when caring for patients with ALD. Social, psychological and clinical issues influence each other and only a wide overview can obtain noteworthy results.

\section{Conflict of interest}

No potential conflict of interest relevant to this article was reported.

\section{REFERENCES}

1. European Association for the Study of the Liver. EASL clinical practice guidelines: management of alcoholrelated liver disease. J Hepatol 2018;69:154-181.

2. American Psychiatric Association. Diagnostic and Statistical Manual of Mental Disorders DSM- $5^{\text {TM }} \cdot 5^{\text {th }}$ ed. Arlington (VA): American Psychiatric Publishing, 2013.

3. Rehm J, Anderson P, Manthey J, et al. Alcohol use disorders in primary health care: what do we know and where do we go? Alcohol Alcohol 2016;51:422-427.

4. World Health Organization. International Statistical Classification of Diseases and Related Health Problems 1oth Revision [Internet]. Geneva (CH): WHO, c2011 [cited 2020 Mar 5]. Available from: https:/www.who.int/ classifications/icd/ICD1oVolume2_en_2010.pdf.

5. Rehm J, Gmel GE Sr, Gmel G, et al. The relationship between different dimensions of alcohol use and the burden of disease-an update. Addiction 2017;112:968-1001.

6. Department of Health and Human Services, US Department of Agriculture. Dietary Guidelines for Americans 2015-2020. 8th ed. New York (NY): Skyhorse Publishing, 2017.

7. World Health Organization. Global Status Report on Noncommunicable Diseases 2014. Geneva (CH): WHO, 2014 .

8. Bell G, Cremona A. Alcohol and death certification: a survey of current practice and attitudes. Br Med J (Clin Res Ed) 1987;295:95.

9. Shield KD, Rylett M, Rehm J. Public Health Successes and Missed Opportunities: Trends in Alcohol Consumption and Attributable Mortality in the WHO European Region, 1990-2014. Copenhagen (DK): World Health Organization, Regional Office for Europe, 2016.

10. Rehm J, Mathers C, Popova S, Thavorncharoensap M, Teerawattananon Y, Patra J. Global burden of disease and injury and economic cost attributable to alcohol use and alcohol-use disorders. Lancet 2009;373:2223-2233.

11. GBD 2013 Risk Factors Collaborators, Forouzanfar MH, Alexander L, et al. Global, regional, and national comparative risk assessment of 79 behavioural, environmental and occupational, and metabolic risks or clusters of risks in 188 countries, 1990-2013: a systematic analysis for the Global Burden of Disease Study 2013. Lancet 2015;386:2287-2323.

12. World Health Organization. Adolescent Obesity and Related Behaviours: Trends and Inequalities in the WHO European Region, 2002-2014. Copenhagen (DK): World 
Health Organization, Regional Office for Europe, 2017.

13. Sassi F. Tackling Harmful Alcohol Use: Economics and Public Health Policy. Paris (FR): OECD Publishing, 2015.

14. World Health Organization. Food-Based Dietary Guidelines in the WHO European Region. Copenhagen (DK): WHO Regional Office for Europe, 2003.

15. Rehm J, Taylor B, Mohapatra S, et al. Alcohol as a risk factor for liver cirrhosis: a systematic review and metaanalysis. Drug Alcohol Rev 2010;29:437-445.

16. Mathurin P, Bataller R. Trends in the management and burden of alcoholic liver disease. J Hepatol 2015;62:S38-S46.

17. Gao B, Bataller R. Alcoholic liver disease: pathogenesis and new therapeutic targets. Gastroenterology 2011;141:15721585 .

18. Wong RJ, Aguilar M, Cheung R, et al. Nonalcoholic steatohepatitis is the second leading etiology of liver disease among adults awaiting liver transplantation in the United States. Gastroenterology 2015;148:547-555.

19. Burra P, Senzolo M, Adam R, et al. Liver transplantation for alcoholic liver disease in Europe: a study from the ELTR (European Liver Transplant Registry). Am J Transplant 2010;10:138-148.

20. Merion RM, Schaubel DE, Dykstra DM, Freeman RB, Port FK, Wolfe RA. The survival benefit of liver transplantation. Am J Transplant 2005;5:307-313.

21. Addolorato G, Bataller R, Burra P, et al. Liver transplantation for alcoholic liver disease. Transplantation 2016;100:981-987.

22. Gallegos-Orozco JF, Charlton MR. Alcoholic liver disease and liver transplantation. Clin Liver Dis 2016;20:521-534.

23. European Association for the Study of the Liver. EASL clinical practice guidelines: liver transplantation. J Hepatol 2016;64:433-485.

24. European Association for the Study of Liver. EASL clinical practical guidelines: management of alcoholic liver disease. J Hepatol 2012;57:399-420.

25. Donckier V, Lucidi V, Gustot T, Moreno C. Ethical considerations regarding early liver transplantation in patients with severe alcoholic hepatitis not responding to medical therapy. J Hepatol 2014;60:866-871.

26. Marroni CA. Management of alcohol recurrence before and after liver transplantation. Clin Res Hepatol Gastroenterol 2015;39 Suppl 1:S109-S114.

27. De Gottardi A, Spahr L, Gelez P, et al. A simple score for predicting alcohol relapse after liver transplantation: results from 387 patients over 15 years. Arch Intern Med
2007;167:1183-1188.

28. Pfitzmann R, Schwenzer J, Rayes N, Seehofer D, Neuhaus $\mathrm{R}$, Nussler NC. Long-term survival and predictors of relapse after orthotopic liver transplantation for alcoholic liver disease. Liver Transpl 2007;13:197-205.

29. Burra P, Lucey MR. Liver transplantation in alcoholic patients. Transpl Int 2005;18:491-498.

30. Zalewska K. Liver advisory group alcohol guidelines [Internet]. Bristol (UK): NHS Organ Donation, 2008 [cited 2020 Mar 5]. Available from: http://odt.nhs.uk/pdf/liver_ selection_policy.pdf.

31. Kotlyar DS, Burke A, Campbell MS, Weinrieb RM. A critical review of candidacy for orthotopic liver transplantation in alcoholic liver disease. Am J Gastroenterol 2008;103:734-743.

32. Gaglio PJ Jr, Gaglio PJ Sr. Complications in patients with alcohol-associated liver disease who undergo liver transplantation. Clin Liver Dis 2012;16:865-875.

33. Kim WR, Lake JR, Smith JM, et al. OPTN/SRTR 2016 annual data report: liver. Am J Transplant 2018;18 Suppl 1:172-253.

34. Singal AK, Charlton MR. Nutrition in alcoholic liver disease. Clin Liver Dis 2012;16:805-826.

35. Jepsen P, Lash TL, Vilstrup H. The clinical course of alcoholic cirrhosis: development of comorbid diseases. A Danish nationwide cohort study. Liver Int 2016;36:16961703.

36. Purnak T, Yilmaz Y. Liver disease and malnutrition. Best Pract Res Clin Gastroenterol 2013;27:619-629.

37. Singal AK, Guturu P, Hmoud B, Kuo YF, Salameh H, Wiesner RH. Evolving frequency and outcomes of liver transplantation based on etiology of liver disease. Transplantation 2013;95:755-760.

38. Berlakovich GA. Challenges in transplantation for alcoholic liver disease. World J Gastroenterol 2014;20:80338039.

39. Kasper DL, Fauci AS, Hauser SL, Longo DL, Jameson JL, Loscalzo J. Harrison's Manual of Medicine. 19th ed. New York (NY): McGraw Hill, 2016.

40. Kortas DY, Haas LS, Simpson WG, Nickl NJ 3rd, Gates LK Jr. Mallory-Weiss tear: predisposing factors and predictors of a complicated course. Am J Gastroenterol 2001;96:2863-2865.

41. Szabo G, Mandrekar P, Oak S, Mayerle J. Effect of ethanol on inflammatory responses: implications for pancreatitis. Pancreatology 2007;7:115-123.

42. Donnadieu-Rigole H, Mura T, Portales P, et al. Effects 
of alcohol withdrawal on monocyte subset defects in chronic alcohol users. J Leukoc Biol 2016;100:1191-1199.

43. Hassan AN. Patients with alcohol use disorder co-occurring with depression and anxiety symptoms: diagnostic and treatment initiation recommendations. J Clin Psychiatry 2018;79:17ac11999.

44. Martin P, DiMartini A, Feng S, Brown R Jr, Fallon M. Evaluation for liver transplantation in adults: 2013 practice guideline by the American Association for the Study of Liver Diseases and the American Society of Transplantation. Hepatology 2014;59:1144-1165.

45. Ursic-Bedoya J, Faure S, Donnadieu-Rigole H, Pageaux GP. Liver transplantation for alcoholic liver disease: lessons learned and unresolved issues. World J Gastroenterol 2015;21:10994-11002.

46. Dasarathy S. Nutrition and alcoholic liver disease: effects of alcoholism on nutrition, effects of nutrition on alcoholic liver disease, and nutritional therapies for alcoholic liver disease. Clin Liver Dis 2016;20:535-550.

47. McClain CJ, Barve SS, Barve A, Marsano L. Alcoholic liver disease and malnutrition. Alcohol Clin Exp Res 2011;35:815-820.

48. Tsien C, Garber A, Narayanan A, et al. Post-liver transplantation sarcopenia in cirrhosis: a prospective evaluation. J Gastroenterol Hepatol 2014;29:1250-1257.

49. Dasarathy S. Posttransplant sarcopenia: an underrecognized early consequence of liver transplantation. Dig Dis Sci 2013;58:3103-3111.

50. Mazurak VC, Tandon P, Montano-Loza AJ. Nutrition and the transplant candidate. Liver Transpl 2017;23:1451-1464.

51. Caly WR, Strauss E, Carrilho FJ, Laudanna AA. Different degrees of malnutrition and immunological alterations according to the aetiology of cirrhosis: a prospective and sequential study. Nutr J 2003;2:10.

52. Testino G, Burra P, Bonino F, et al. Acute alcoholic hepatitis, end stage alcoholic liver disease and liver transplantation: an Italian position statement. World J Gastroenterol 2014;20:14642-14651.

53. Dutkowski P, Linecker M, DeOliveira ML, Mullhaupt B, Clavien PA. Challenges to liver transplantation and strategies to improve outcomes. Gastroenterology 2015;148:307323.

54. Rustad JK, Stern TA, Prabhakar M, Musselman D. Risk factors for alcohol relapse following orthotopic liver transplantation: a systematic review. Psychosomatics 2015;56:21-35.
55. Gramenzi A, Biselli M, Andreone P. Authors' reply: comment to "liver transplantation for patients with alcoholic liver disease: an open question". Dig Liver Dis 2013;45:81.

56. Chuncharunee L, Yamashiki N, Thakkinstian A, Sobhonslidsuk A. Alcohol relapse and its predictors after liver transplantation for alcoholic liver disease: a systematic review and meta-analysis. BMC Gastroenterol 2019;19:150.

57. Egawa H, Nishimura K, Teramukai S, et al. Risk factors for alcohol relapse after liver transplantation for alcoholic cirrhosis in Japan. Liver Transpl 2014;20:298-310.

58. Kelly M, Chick J, Gribble R, et al. Predictors of relapse to harmful alcohol after orthotopic liver transplantation. Alcohol Alcohol 2006;41:278-283.

59. Karim Z, Intaraprasong P, Scudamore CH, et al. Predictors of relapse to significant alcohol drinking after liver transplantation. Can J Gastroenterol 2010;24:245-250.

6o. Pageaux GP, Michel J, Coste V, et al. Alcoholic cirrhosis is a good indication for liver transplantation, even for cases of recidivism. Gut 1999;45:421-426.

61. Osorio RW, Ascher NL, Avery M, Bacchetti P, Roberts JP, Lake JR. Predicting recidivism after orthotopic liver transplantation for alcoholic liver disease. Hepatology 1994;20:105-110.

62. Hartl J, Scherer MN, Loss M, et al. Strong predictors for alcohol recidivism after liver transplantation: nonacceptance of the alcohol problem and abstinence of $<3$ months. Scand J Gastroenterol 2011;46:1257-1266.

63. Askgaard G, Tolstrup JS, Gerds TA, Hamberg O, Zierau L, Kjaer MS. Predictors of heavy drinking after liver transplantation for alcoholic liver disease in Denmark (1990-2013): a nationwide study with competing risks analyses. Scand J Gastroenterol 2016;51:225-235.

64. Rodrigue JR, Hanto DW, Curry MP. Substance abuse treatment and its association with relapse to alcohol use after liver transplantation. Liver Transpl 2013;19:1387-1395.

65. Im GY, Cameron AM, Lucey MR. Liver transplantation for alcoholic hepatitis. J Hepatol 2019;70:328-334.

66. Dew MA, DiMartini AF, Steel J, et al. Meta-analysis of risk for relapse to substance use after transplantation of the liver or other solid organs. Liver Transpl 2008;14:159-172.

67. Leong J, Im GY. Evaluation and selection of the patient with alcoholic liver disease for liver transplant. Clin Liver Dis 2012;16:851-863.

68. United Network for Organ Sharing (UNOS). Minimal criteria for liver transplantation 2003 [Internet]. Richmond (VA): 
UNOS, c2020 [cited 2020 Mar 5]. Available from: https:// unos.org/wp-content/uploads/unos/Liver_patient.pdf.

69. Testino G, Leone S, Sumberaz A, Borro P. Liver transplantation in alcoholic patients. Alcohol Clin Exp Res 2014;38:1800-1802.

70. Faure S, Herrero A, Jung B, et al. Excessive alcohol consumption after liver transplantation impacts on longterm survival, whatever the primary indication. J Hepatol 2012;57:306-312.

71. Vaillant GE. A 6o-year follow-up of alcoholic men. Addiction 2003;98:1043-1051.

72. Kodali S, Kaif M, Tariq R, Singal AK. Alcohol relapse after liver transplantation for alcoholic cirrhosis-impact on liver graft and patient survival: a meta-analysis. Alcohol Alcohol 2018;53:166-172.

73. Cuadrado A, Fabrega E, Casafont F, Pons-Romero F. Alcohol recidivism impairs long-term patient survival after orthotopic liver transplantation for alcoholic liver disease. Liver Transpl 2005;11:420-426.

74. Rice JP, Lucey MR. Should length of sobriety be a major determinant in liver transplant selection? Curr Opin Organ Transplant 2013;18:259-264.

75. Marroni CA, Fleck AM Jr, Fernandes SA, et al. Liver transplantation and alcoholic liver disease: History, controversies, and considerations. World J Gastroenterol 2018;24:2785-2805.

76. Litten RZ, Bradley AM, Moss HB. Alcohol biomarkers in applied settings: recent advances and future research opportunities. Alcohol Clin Exp Res 2010;34:955-967.

77. Burra P, Rodriguez-Castro KI. Neoplastic disease after liver transplantation: focus on de novo neoplasms. World J Gastroenterol 2015;21:8753-8768.

78. Madhwal S, Atreja A, Albeldawi M, Lopez R, Post A, Costa MA. Is liver transplantation a risk factor for cardiovascular disease? A meta-analysis of observational studies. Liver Transpl 2012;18:1140-1146.

79. Desai S, Hong JC, Saab S. Cardiovascular risk factors following orthotopic liver transplantation: predisposing factors, incidence and management. Liver Int 2010;30:948957.

8o. Hong JC, Kahan BD. Immunosuppressive agents in organ transplantation: past, present, and future. Semin Nephrol 2000;20:108-125.

81. Canzanello VJ, Schwartz L, Taler SJ, et al. Evolution of cardiovascular risk after liver transplantation: a comparison of cyclosporine A and tacrolimus (FK506).
Liver Transpl Surg 1997;3:1-9.

82. Di Maira T, Rubin A, Puchades L, et al. Framingham score, renal dysfunction, and cardiovascular risk in liver transplant patients. Liver Transpl 2015;21:812-822.

83. Watt KD, Charlton MR. Metabolic syndrome and liver transplantation: a review and guide to management. J Hepatol 2010;53:199-206.

84. Lucey MR, Terrault N, Ojo L, et al. Long-term management of the successful adult liver transplant: 2012 practice guideline by the American Association for the Study of Liver Diseases and the American Society of Transplantation. Liver Transpl 2013;19:3-26.

85. Albeldawi M, Aggarwal A, Madhwal S, et al. Cumulative risk of cardiovascular events after orthotopic liver transplantation. Liver Transpl 2012;18:370-375.

86. Watt KD, Pedersen RA, Kremers WK, Heimbach JK, Sanchez W, Gores GJ. Long-term probability of and mortality from de novo malignancy after liver transplantation. Gastroenterology 2009;137:2010-2017.

87. Chandok N, Watt KD. Burden of de novo malignancy in the liver transplant recipient. Liver Transpl 2012;18:12771289.

88. Sanchez W, Talwalkar JA, Gores GJ. "Will all liver transplantation patients eventually die from cancer?". J Hepatol 2006;44:13-18.

89. Watt KD, Pedersen RA, Kremers WK, Heimbach JK, Charlton MR. Evolution of causes and risk factors for mortality post-liver transplant: results of the NIDDK long-term follow-up study. Am J Transplant 2010;10:14201427.

90. Schrem H, Kurok M, Kaltenborn A, et al. Incidence and long-term risk of de novo malignancies after liver transplantation with implications for prevention and detection. Liver Transpl 2013;19:1252-1261.

91. Verran DJ, Mulhearn MH, Dilworth PJ, et al. Nature and outcomes of the increased incidence of colorectal malignancy after liver transplantation in Australasia. Med J Aust 2013;199:610-612.

92. Baccarani U, Adani GL, Serraino D, et al. De novo tumors are a major cause of late mortality after orthotopic liver transplantation. Transplant Proc 2009;41:1303-1305.

93. Soulillou JP, Giral M. Controlling the incidence of infection and malignancy by modifying immunosuppression. Transplantation 2001;72:S89-S93.

94. Dantal J, Hourmant M, Cantarovich D, et al. Effect of long-term immunosuppression in kidney-graft recipi- 
ents on cancer incidence: randomised comparison of two cyclosporin regimens. Lancet 1998;351:623-628.

95. Mithoefer AB, Supran S, Freeman RB. Risk factors associated with the development of skin cancer after liver transplantation. Liver Transpl 2002;8:939-944.

96. Saigal S, Norris S, Muiesan P, Rela M, Heaton N, O'Grady J. Evidence of differential risk for posttransplantation malignancy based on pretransplantation cause in patients undergoing liver transplantation. Liver Transpl 2002;8:482-487.

97. Cogliano VJ, Baan R, Straif K, et al. Preventable exposures associated with human cancers. J Natl Cancer Inst 2011;103:1827-1839.

98. Benlloch S, Berenguer M, Prieto M, et al. De novo internal neoplasms after liver transplantation: increased risk and aggressive behavior in recent years? Am J Transplant 2004;4:596-604.

99. Jimenez C, Manrique A, Marques E, et al. Incidence and risk factors for the development of lung tumors after liver transplantation. Transpl Int 2007;20:57-63.

100. Jain A, DiMartini A, Kashyap R, Youk A, Rohal S, Fung J. Long-term follow-up after liver transplantation for alcoholic liver disease under tacrolimus. Transplantation 2000;70:1335-1342.

101. Bellamy CO, DiMartini AM, Ruppert K, et al. Liver transplantation for alcoholic cirrhosis: long term followup and impact of disease recurrence. Transplantation 2001;72:619-626.

102. Castelli E, Hrelia P, Maffei F, et al. Indicators of genetic damage in alcoholics: reversibility after alcohol abstinence. Hepatogastroenterology 1999;46:1664-1668.

103. Franceschi S, Talamini R, Barra S, et al. Smoking and drinking in relation to cancers of the oral cavity, pharynx, larynx, and esophagus in northern Italy. Cancer Res 1990;50:6502-6507.

104. Lucey MR, Schaubel DE, Guidinger MK, Tome S, Merion RM. Effect of alcoholic liver disease and hepatitis C infection on waiting list and posttransplant mortality and transplant survival benefit. Hepatology 2009;50:400-406.

105. Testino G, Vignoli T, Patussi V, Scafato E, Caputo F; SIA board (Appendix A) and the external expert supervisors (Appendix B). Management of end-stage alcohol-related liver disease and severe acute alcohol-related hepatitis: position paper of the Italian Society on Alcohol (SIA). Dig Liver Dis 2020;52:21-32.

106. Singal AK, Chaha KS, Rasheed K, Anand BS. Liver transplantation in alcoholic liver disease current status and controversies. World J Gastroenterol 2013;19:59535963.

107. European Liver Transplant Registry (ELTR). Evolution of LTs in Europe [Internet]. Villejuif (FR): ELTR, 2020 [cited 2020 Mar 5]. Available from: http://www.eltr.org/ Evolution-of-LTs-in-Europe.html.

108. Shen NT, Londono C, Gold S, Wu A, Mages KC, Brown RSJ. Systematic review with meta-analysis on transplantation for alcohol-related liver disease: very low evidence of improved outcomes. World J Gastroenterol 2019;25:1628-1639.

109. Mathurin P, Moreno C, Samuel D, et al. Early liver transplantation for severe alcoholic hepatitis. N Engl J Med 2011;365:1790-1800.

110. Im GY, Kim-Schluger L, Shenoy A, et al. Early liver transplantation for severe alcoholic hepatitis in the United States: a single-center experience. Am J Transplant 2016;16:841-849.

111. Gish RG, Lee AH, Keeffe EB, Rome H, Concepcion W, Esquivel CO. Liver transplantation for patients with alcoholism and end-stage liver disease. Am J Gastroenterol 1993;88:1337-1342.

112. Di Martino V, Miguet M, Vanlemmens C, et al. Impact of liver transplantation (LT) on alcohol consumption (AC) in patients with Pugh B cirrhosis: a randomized study. J Hepatol 2004;40(Suppl 1):44.

113. Lucey MR, Mathurin P, Morgan TR. Alcoholic hepatitis. N Engl J Med 2009;360:2758-2769.

114. Nguyen TA, DeShazo JP, Thacker LR, Puri P, Sanyal AJ. The worsening profile of alcoholic hepatitis in the United States. Alcohol Clin Exp Res 2016;40:1295-1303.

115. Crabb DW, Bataller R, Chalasani NP, et al. Standard definitions and common data elements for clinical trials in patients with alcoholic hepatitis: recommendation from the NIAAA alcoholic hepatitis consortia. Gastroenterology 2016;150:785-790.

116. Yang AL, Vadhavkar S, Singh G, Omary MB. Epidemiology of alcohol-related liver and pancreatic disease in the United States. Arch Intern Med 2008;168:649-656.

117. Thursz MR, Richardson P, Allison M, et al. Prednisolone or pentoxifylline for alcoholic hepatitis. N Engl J Med 2015;372:1619-1628.

118. Louvet A, Naveau S, Abdelnour M, et al. The Lille model: a new tool for therapeutic strategy in patients with severe alcoholic hepatitis treated with steroids. Hepatology 
2007;45:1348-1354.

119. Papastergiou V, Tsochatzis EA, Pieri G, et al. Nine scoring models for short-term mortality in alcoholic hepatitis: cross-validation in a biopsy-proven cohort. Aliment Pharmacol Ther 2014;39:721-732.

120. Mathurin P, O'Grady J, Carithers RL, et al. Corticosteroids improve short-term survival in patients with severe alcoholic hepatitis: meta-analysis of individual patient data. Gut 2011;60:255-26o.

121. Singal AK, Bashar H, Anand BS, Jampana SC, Singal V, Kuo YF. Outcomes after liver transplantation for alcoholic hepatitis are similar to alcoholic cirrhosis: exploratory analysis from the UNOS database. Hepatology 2012;55:1398-1405.

122. Al-Saeedi M, Barout MH, Probst $P$, et al. Meta-analysis of patient survival and rate of alcohol relapse in livertransplanted patients for acute alcoholic hepatitis. Langenbecks Arch Surg 2018;403:825-836.

123. Schlagintweit HE, Lynch MJ, Hendershot CS. A review of behavioral alcohol interventions for transplant candidates and recipients with alcohol-related liver disease. Am J Transplant 2019;19:2678-2685.

124. Caputo F, Domenicali M, Bernardi M. Diagnosis and treatment of alcohol use disorder in patients with endstage alcoholic liver disease. Hepatology 2019;70:410-417.

125. Weinrieb RM, Van Horn DH, McLellan AT, et al. Alcoholism treatment after liver transplantation: lessons learned from a clinical trial that failed. Psychosomatics 2001;42:110-116.

126. Attilia ML, Lattanzi B, Ledda R, et al. The multidisciplinary support in preventing alcohol relapse after liver transplantation: a single-center experience. Clin Transplant 2018;32:e13243.

127. Erim Y, Bottcher M, Schieber K, et al. Feasibility and acceptability of an alcohol addiction therapy integrated in a transplant center for patients awaiting liver transplantation. Alcohol Alcohol 2016;51:40-46.

128. Addolorato G, Mirijello A, Leggio L, et al. Liver transplantation in alcoholic patients: impact of an alcohol addiction unit within a liver transplant center. Alcohol Clin Exp Res 2013;37:1601-1608.

129. Hendershot CS, Witkiewitz K, George WH, Marlatt GA. Relapse prevention for addictive behaviors. Subst Abuse Treat Prev Policy 2011;6:17.

130. Witkiewitz K, Marlatt GA. Relapse prevention for alcohol and drug problems: that was Zen, this is Tao. Am Psychol 2004;59:224-235.

131. Hettema J, Steele J, Miller WR. Motivational interviewing. Annu Rev Clin Psychol 2005;1:91-111.

132. Weinrieb RM, Van Horn DH, McLellan AT, Volpicelli JR, Calarco JS, Lucey MR. Drinking behavior and motivation for treatment among alcohol-dependent liver transplant candidates. J Addict Dis 2001;20:105-119.

133. Zhu J, Chen PY, Frankel M, Selby RR, Fong TL. Contemporary policies regarding alcohol and marijuana use among liver transplant programs in the United States. Transplantation 2018;102:433-439.

134. Masson S, Marrow B, Kendrick S, Elsharkawy AM, Latimer S, Hudson M. An 'alcohol contract' has no significant effect on return to drinking after liver transplantation for alcoholic liver disease. Transpl Int 2014;27:475-481.

135. Golfieri L, Gitto S, Vukotic R, et al. Impact of psychosocial status on liver transplant process. Ann Hepatol 2019;18:804809 . 